JELTL (Journal of English Language Teaching and Linguistics) e-ISSN: 2502-6062, p-ISSN: 2503-1848

2020, Vol. 5(2)

www.jeltl.org

\title{
An Ecological Perspective on Reading Development: A Theoretical Framework to Guide Empirical Research
}

\author{
Nadori Neirouz \\ Chouaib Doukkali University, El-Jadida, Morocco \\ e-mail:nadori_neirouz@hotmailcom
}

\begin{abstract}
Recent efforts have addressed the new challenges related to conceptualizing, understanding and improving reading competency. Several literacy researchers have perceived reading as a developmental skill that is not situated exclusively within student's cognition, or within family processes, or within classroom or school processes. Rather, reading development has been viewed as a result of the dynamic interaction among reader, family, classroom, and school system (Jaeger, 2017). Following on from this, systems theory approach and more specifically the ecological model allows for the examination of reading skill development from a holistic perspective. It provides an inclusive frame for describing and explaining how the educational opportunities are distributed at the micro, meso, exo, and macro systems and how these systems interact to explain students' reading differences. It also delineates how developing readers' individual characteristics transact with both proximal and distal processes to craft their reading ecologies. Future policy, practice and research are recommended to be based on the ecological model premises to have a comprehensive view of reading development.
\end{abstract}

Keywords: Systems theory approach, ecological model, and reading skill development

\section{INTRODUCTION}

More than any other skill, reading is substantial to successfully navigating the curriculum and vital to every students' growth and maturation. It is essential to shaping individuals' trajectories through life, their economic well being, and the ability to actively and fully participate in broader society (OECD, 2019; Martin, Mullis \& Hooper, 2017). An extensive range of theories has influenced research on reading.

Among the broad and influential theories that have had a significant effect on reading research are behaviorism, constructivism, information/cognitive processing theories, 


\section{Nadori Neirouz}

sociocognitive theory, sociocultural theory, and system theory. From the behaviorism perspective, reading is viewed as conditioned behavior and just another process susceptible to programming. From a behaviorist perspective, reading is not a result of growth or development, but rather a consequence of an acquired behavior influenced by certain environmental contingencies (Hedgcock \& Ferris, 2018). The transition in the view of language acquisition from conditioned behavior to natural process inevitably resounded in the reading research among psycholinguists (Goodman, 1965). They have emphasized the importance of how meaning is acquired, represented, and utilized during the process of reading. As a result, learning to read, the written counterpart of acquiring an oral language, is regarded as an inherent ability rather than a reflective process requiring repetitive reinforcements of a set of skills.

Later, on the basis of research published between 1976 and 1985, it was cognitive psychology, and more specifically information-processing theory, that dominated the domain of reading (Anderson, 1978). Based on this theory, the information-processing researchers advocate that the readers' knowledge base is powerful, pervasive, individualistic, and malleable. Strong connection is established between readers' prior knowledge and their subsequent reading achievement, comprehension, memory, and strategic processing (Stanovich, 1986; Sadoski, 2018). The explanatory adequacy of the computer metaphor that has guided the information-processing-based research of the previous decade is perceived as unsatisfactory. Specifically, the earlier information-processing approach is restored by a constructivist theory that recognizes reading as individualistic and socially embedded and hence discards the mechanistic views of learning to read. Within the constructivist approach, reading is based on knowledge conception and that this knowledge does not involve singular construct but exist in various forms and interactive dimensions. Readers construct new knowledge when they interact with others or with objects.

Today systems theory provides a holistic perspective to understanding reading development. Systems theory researchers have considered reading as a process which evolves through time and which is inextricably embedded in manifold interconnected individual and contextual patterns (e.g., Lerner \& Overton, 2008; Bronfenbrenner, 2005, 2006).Interpreting students' reading achievement necessitates an examination of how individual and contextual influences combine to provide a holistic examination of reading development.

The following is a discussion of the fundamental components underlying systems theory and how it relates to reading. More specifically, the present study draws on Bronfenbrenner and Morris's (2006) bioecological systems theory basic principles to demonstrate how reading development occur through what happens in the school, the classroom, and the home and through interactions among the individual student, parents, teachers, school principals, and peers.

\section{SYSTEMS THEORY APPROACH TO READING DEVELOPMENT}

The systems theory approach to reading development seeks to describe, explain, and optimize key outcomes by investigating the complex interactions between an active and evolving learner and the persons and objects in the surrounding environment (Bronfenbrenner \& Morris, 2006). This approach provides a holistic-systemic perspective upholds multidimentional aspects of analysis. In this respect, Overton (2013) contends: 
This framework [system theory] further replaces the epistemology of atomism and reductionism with holism and system analyses; splitting with relations; foundational elements with networks, and unidirectional, linear, additive associative or causal sequences with emergent directional sequences entailing nonlinear nonadditive reciprocal and circular feedback systems. This framework is the world view of relationism and midrange metatheory-methodology of relational development at systems. (p.26)

Accordingly, this theory recognizes the concept of holism as a fundamental guiding principle. Unlike previous studies which adopted fixed, atomistic views to study elements that affect individual's reading development regardless of context, systems theory views reading as being substantially linked to context in which they are embedded. Studies analyzing reading ecologies as distinct, separable, and independent elementary components tend to either over-emphasize or under-emphasize their contributions (Shute \& Slee, 2015). Only research that can value learners and their ecologies within a single set of analysis can simultaneously contrast the effects of multiple contexts and assess their differential contributions. Therefore, "single aspects do not develop and function in isolation, and they should not be divorced from totality in analysis" (Magnusson \& Cairns, 1996, p. 12).

Another central aspect of systems theory is the notion of reciprocal influence occurring between the learner and his/her environment overtime. The reciprocal influence is clearly seen in the way the individuals are shaped and defined by the contexts in which they function and the effects they have on these contexts to construct more favorable environments for growth (Bronfenbrenner, 2004). This concept of mutual influence provides a shift from theories viewing the reader as passively acted upon by the environment to theories admitting the reader's contribution to the environment.

Open systems represents an additional key aspect of systems theory that may influence learners' developmental outcomes. According to Thelen and Smith (1998), development should be contextualized and the notion of "open system" necessitates an interchange between the individual and the contexts (as cited in Shute \& Slee, 2015). Therefore, learners, families, schools, peer groups and community are all considered as open systems interacting with each other and influencing behaviors. Therefore, the behavior (reading achievement) is not just the result of ability or lack of it, it is a window through which one can look to understand factors contributing to this result and provide a significant insight into various roles and relations within the system (Shute \& Slee, 2015).

\section{A BIOECOLOGICAL SYSTEMS PERSPECTIVE ON READING DEVELOPMENT}

Bronfenbrenner bioecological model is framed within systems theory and is based on person, process, context, and time components (PPCT) (Bronfenbrenner \& Morris, 2006). These components help identify a) the role learner's characteristics play in the development of reading namely, person variables (self-efficacy, self-regulation), b) the social interactions influencing reading development designated as process variables (parentstudents, teacher-students, teacher-parents' interactions), c) the effects of the environments 


\section{Nadori Neirouz}

within which the students reside identified as context variables (home, school, neighborhood), and d) the influence of time named time variable (the amount of time spent in reading interaction, the length and frequency of the reading practice, the amount of the reading curriculum covered during the school year) (Bronfenbrenner \& Morris, 2006, p. 795). The following is a detailed discussion of the bioecological model components beginning with the innermost of the nested system element (the developing reader) moving to proximal processes, contextual systems, and finally, the role of time.

\subsection{The role of the developing reader}

Bronfenbrenner argues that research using his model overemphasized the role of contextual aspects and downplayed the role of the developing individual. He claims, 'In place of too much research on development out of context, we now have a surfeit of studies on context without development' (Bronfenbrenner, 1986, p.288). Bronfenbrenner categorizes personal characteristics into demand, resource, and force components. These personal characteristics determine the direction, power, and development of proximal processes over time (Bronfenbrenner \& Morris, 2006, p. 795). Demand characteristics namely, age, gender, and other aspects of behavior regulate reactions from the environment. Those reactions are likely to enhance or hamper skill development. Next, resource attributes are necessary for quality functioning of proximal processes and encompass particular ability, experience, knowledge and skill among other resource characteristics. Although these attributes are not explicit, they are more powerful in shaping behavior compared with demand characteristics. Finally, force characteristics are associations of cognitive, emotional, and motivational aspects. Bronfenbrenner recognizes self-efficacy as an important component of force characteristic and formulates this concept as "directive belief systems about oneself" (Bronfenbrenner \& Morris, 2006, p. 811). The bioecological model emphasizes the potential of this force attribute and conceptualizes it as "directional dispositions interacting synergistically with particular successive levels of developmental advance" (Bronfenbrenner $\&$ Morris, 2006, p.811). The figure below illustrates this point:

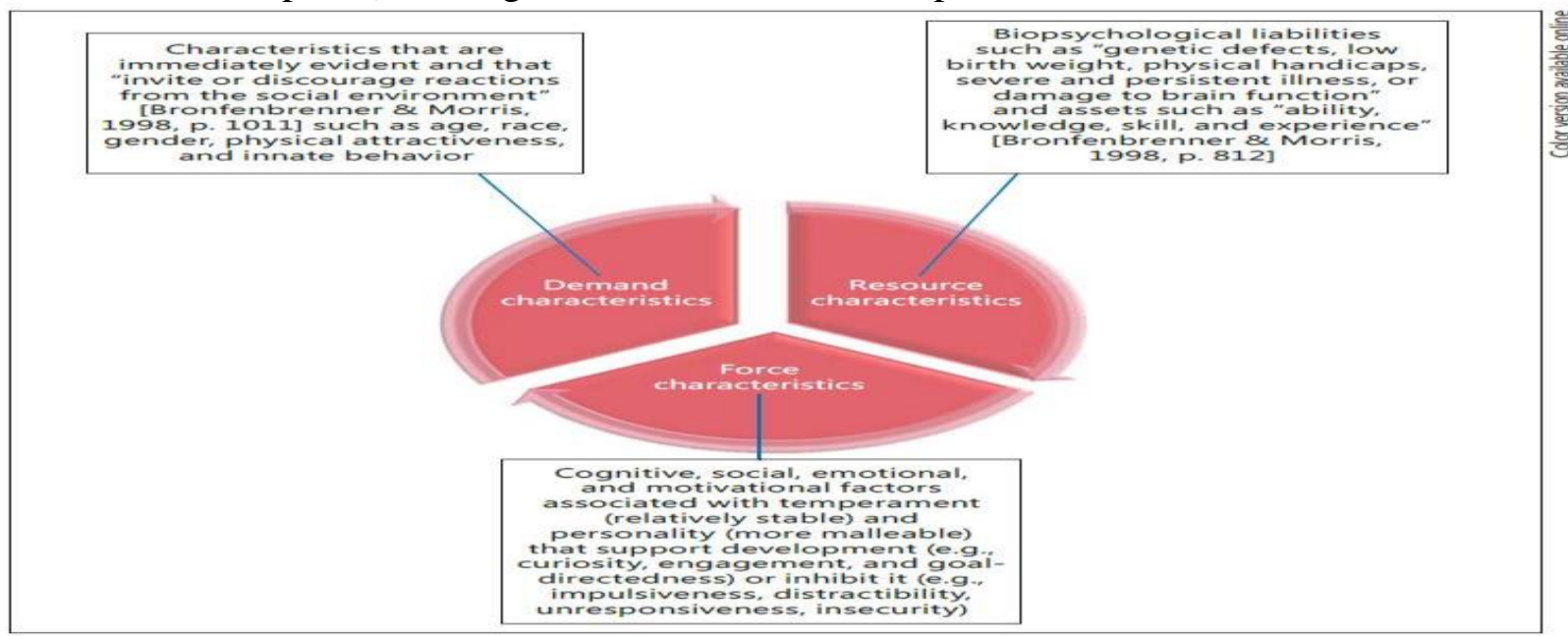

Figure 1: The reader personal characteristics (cited in Jaeger, 2017, p. 175) 
Based on this reasoning, the reader has distinctive demand, resource, and force characteristics. The current study limits itself to the discussion of force characteristics of the developing reader namely, perceived self-efficacy and self regulation and their unique and cumulative contribution in explaining reading achievement. These two affect assets interact in a dynamic way and reciprocally influence each other (Zimmerman \& Kitsantas, 2014). Students with high reading self-efficacy perceptions have a tendency to deploy a wide range of effective reading strategies and therefore become more self-regulated in their reading process (Nadori, 2020). In the same way, students with high self-regulatory competence successfully monitor, direct, and control their reading practice which in turn raises their perceptions about their reading abilities. In line with systems theory and Bronfenbrenner's ecological model, perceived reading self-efficacy and self- regulation are considered as dynamic processes growing in complexity over time. As readers get involved in constructive interactions with the environment (parents, teachers, and peer groups) they internalize the reading skills and knowledge necessary for the fulfillment of the reading activity, extend their self-regulatory skills progressively, and enhance their reading self-efficacy perceptions.

Reading self-efficacy beliefs and self-regulation do not only have a direct effect on reading achievement variance, they also operate as mediating factors between the environments in which the readers develop and their reading outcomes (Cheung, 2015; Cheung \& Lai, 2013). Positive and supportive connections with the environment allow readers to grow self-efficacious and develop positive perceptions towards reading. A supportive person with a high sense of caring and commitment to the developing reader has some bearing on the development of readers' personal attributes. In this sense, effective parenting styles including parents' goals and strategies in child-rearing may boost selfefficacy perceptions. Further, supportive teacher-student relations and productive classroom climate may have practical implications for the development of readers' perceived selfefficacy and their self-regulatory strategies. Consequently, readers with high perceived selfefficacy and self-regulation display more engagement in a reading activity and are likely to approach a reading task with more confidence and determination. These force characteristics (psychological factors) have important implications for explaining and predicting the reading behavior. In effect, the reading behavior draws upon these psychological assets to inform the level and quality of interaction with the environment (people, tools, and symbols), perceptions towards the reading practice, and the way to approach and interact with the reading material.

Readers' psychological assets are malleable factors that can be adjusted by instruction and through the creation of encouraging and favorable learning environments (Unrau et al., 2018). It is therefore the teachers' role to consider students' personal attributes and conduct surveys assessing areas such as self-efficacy and self-regulation before designing or implementing the reading activity. Also, emphasized is the potential of instruction in helping readers elevate their levels of self-efficacy and strategy use. Increased levels of self-efficacy perceptions and self-regulatory use of strategies allow readers to interact efficiently with the text, develop core-analytical skills, and move gradually from lower-order to higher-order skills. Additionally, parents should understand the role and operation of key personal attributes of their children and provide supportive and encouraging home environments. 


\section{Nadori Neirouz}

The bioecological model therefore suggests that understanding significant person or dispositional variables that readers possess can help shape and inform the creation of effective reading environments and hence increase reading achievement. These psychological assets (self-efficacy and self- regulation) act together to produce positive reading outcomes. Considering only personal attributes for explaining the complex developmental aspects of reading is insufficient. Bronfenbrenner and Morris believe that it is a prerequisite to account for both personal and environmental factors and to investigate the nature of interaction occurring between them (Bronfenbrenner \& Morris, 2006, p. 797) to understand and explain any developmental outcome. The interactions between the individuals and their immediate contexts (parents, teachers, and peers) are referred to as proximal processes.

\subsection{The role of proximal processes}

Bronfenbrenner and Morris (2006) argue that development and learning take place as a result of processes characterized by repetitive and reciprocal forms of interaction among an active and evolving organism, objects, and symbols in the proximal environment (Bronfenbrenner \& Morris, 2006, p. 795). Bornfenbrenner and Morris (2006) postulate that:

The form, power, content, and direction of the proximal processes effecting development vary systematically as joint function of the characteristics of the developing person and the environment-both immediate and more remote- in which the processes are taking place, the nature of the developmental outcomes under consideration, and the social continuities and changes occurring over time through the life course and the historical period during which the person has lived. (p. 798)

The proximal processes are considered as driving forces of development and patterns which allow students to develop self-control, increase self-efficacy perceptions, cope with stressful situations, and learn new knowledge and skills. These processes drive students beyond their current level of functioning, and in this way, approximate Vygotsky's (1978) zone of proximal development. Although Vygotsky's zone of proximal development and Bronfenbrenner's proximal processes are similar in some ways, Bronfenbrenner provides a detailed description of how the aspects of proximal processes operate in differing proximal contexts.

The proximal process patterns have several key features that require clarification and careful interpretation. First, all transactions between person-to-person and person-to object/symbol are reciprocal. The students, for instance, both influence and are influenced by their teachers' reading instructions and practices. In other words, students' level of engagement in a reading course influences the teacher's choice of text complexity level, the amount of time spent on the reading activity, and the type of the activity. Second, proximal processes increase in complexity; in the above example, the teacher selects less complex reading texts one day and more challenging ones a week later. Third, the interaction can happen between the student and another person, but it can also occur with objects. For this interaction to be effective, objects such as print material or digital texts should stimulate 
"attention, exploration, manipulation, elaboration, and imagination" (Bronfenbrenner\& Morris, 1998, p. 997). Time variable plays an important role in determining the quality of proximal processes. Effective interactions occurring in proximal processes are those which take place "on a fairly regular basis, over an extended period of time" (Bronfenbrenner \& Morris, 2006, p. 798). Figure 2 illustrates how the readers' proximal processes operate:

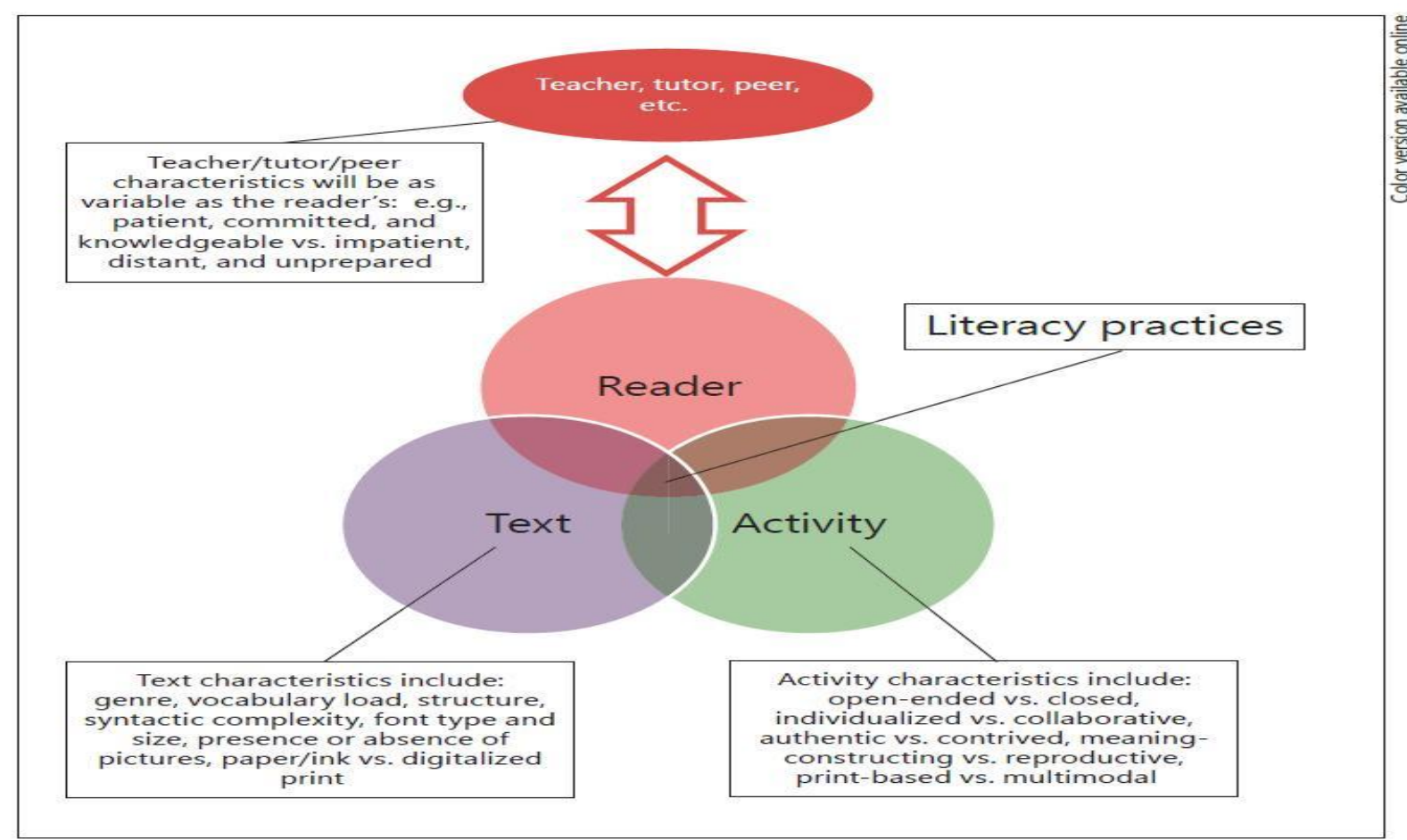

Figure 2: The reader within school-based proximal processes (Adapted from Jaeger, 2017, p. 176)

The relevance of proximal processes for reading development lies in effective interactions the reader establishes with teachers, peers, parents, objects (i.e., as books and Ipads), and symbols (i.e., print and pictures). Reading-related proximal processes function on a regular basis and are characterized by the quality of relations between the individuals involved. These relations are bidirectional in that "initiatives do not come from one side only; there must be some degree of reciprocity in the exchange" (Bronfenbrenner \& Morris, 2006, p. 998). Based on this reasoning, educators/teachers and can build a learning environment to assist proximal processes and provide the requisite support to attain reading expertise. The importance of gradual release of responsibility and appropriate guidance should be emphasized to improve the quality of proximal processes. The teachers' role is therefore to facilitate the reading process and help students take responsibility gradually until they function independently.

Equally important, proximal processes should be adjusted to meet the academic and personal needs of each reader. To support the reading development, teachers and educators should be responsive to the inherent differences among readers and provide a favorable environment to move learning forward. Readers in a classroom have different learning styles and deploy various learning strategies. An important step in this direction could be the 


\section{Nadori Neirouz}

selection of reading tasks and materials that meet the readers' needs and knowledge. In this regard, the teacher should provide individualized instructions taking into account students' differences and characteristics. Further the selected reading material should nurture curiosity, invite attention, enable manipulation, and encourage analytical thinking.

Proximal processes can also be supported by the type of reading activities accomplished in a reading course. A reading activity may generate greater reading gains when a) students are able to use reading for authentic purposes, b) communication and collaborative learning is emphasized, c) students are given the opportunity to set goals, select and organize information, choose a strategy, and assess achievement. In doing so, the developing reader interacts with texts, activities, and other readers on a regular basis optimizing, therefore, requisite reading gains.

The relationships with peers may also influence the reading experience as they serve as proximal process partners. It is of paramount importance to ensure positive and encouraging relationships among readers and their peers. Having unfavorable interactions with peers may obstruct reading development and result into a deficit in the process. Conversely, a positive classroom climate and a strong sense of classroom community allow for positive interactions and optimize reciprocal learning and interchange among readers. Supportive connections between the reader and his/her peers are as important as productive reading activities and rich reading classroom experiences. The importance of students' grouping that occurs within schools should be meticulously dealt with. According to Coleman et al., (1966), "the social composition of the student body is more highly related to achievement, independent of the students' own social background, than is any school factor" (p. 325). Based on this contention, educational policies should be aware of the effects of the presence and the concentration of peers with limited skills or fewer economic resources on students' achievement in general and reading skill development in particular (Aikens, 2008, p. 249).

\subsection{The role of contextual systems}

According to the bioecological model, the individual's behavior is strongly influenced by forces emanating from multiple nested settings and from relations among these settings (Bronfenbrenner\& Morris, 2006, p. 817). Students' reading development can only be understood within the context of a series of nested systems. These systems or ecologies consist of important environments in which readers, teachers, parents, and peers inhabit and are organized and conceptualized into interacting systems, including the microsystem, mesosystem, exosystem, and macrosystem (Jaeger, 2017, p. 177).

Microsystems are considered as proximal contexts in which the reader is an active participant such as home, school, peer group, or neighborhood. These proximal processes constitute the fundamental mechanisms contributing to positive personal attributes (perceived self-efficacy and self regulation) and the enhancement of developmental outcomes (reading achievement). Bronfenbrenner and Evans (2000) postulate that microsystems can be constructive or destructive environments. They describe constructive environments as calm, stable, and relatively predictable, including routines such as nightly reading practice and therefore conductive to development (reading development). Conversely, destructive environments are perceived as disordered, unstable, and chaotic 
settings thereby impeding or slowing down development (Bronfenbrenner \& Evans, 2000, p. 121).

The intersection of two or more microsystems is what Bronfenbrenner called mesosystems. Mesosystems consist of processes and relations occurring between or among two or more settings in the microsystem such as family-school interaction, peers-family interaction, reader-peers interaction, reader-school interaction. Understanding how mesosystems function illuminates the ways in which these environments are interrelated and act together to determine students' reading behavior. At school, the student is required to read academic texts and complete reading-related assignments. This process involves readers' interaction with teachers and/or peers. At home, he/she is involved in reading practices such as reading books, magazines or newspapers. These practices may be processed through interactions with parents and/or siblings. Spending time with peers allows students to engage in the reading of digital texts and communication via social media. The act of reading takes place at the intersection of all the microsystems in which the developing reader is an active member. The reading experience is not situated within a single microsystem. This means that the developing reader has differing experiences depending on the microsystem in which he/she is situated as well as the quality and the nature of interactions in which he/she gets involved.

The mesosystem is essentially a system of microsystems in which key social elements connect to influence behavior. The mesosystem effects provide a clear evidence of how school/teacher-home/parents contexts interact in ways that are relevant to students' development of reading. Schools with positive partnership climates are likely to increase parental involvement at school and at home. Consequently, parents become engaged in their children education if they perceive that schools have effective practices to involve parents at school and at home on homework and reading activities (Epstein, 2018). Bronfenbrenner's model (Bronfenbrenner \& Morris 2006) also suggests that these influences are reciprocal. Increased involvement of parents at school and in joint-reading activities with their children at home supports teacher's reading-related practices at school and vice-versa. Therefore, the mesosystem influences emphasize the potential of understanding how key social environments (home, school, peers) and the nature of interactions between them explain trends in reading achievement.

Positive interactions in the mesosystems have other positive outcomes. Absenteeism and school discipline problems are reduced when strong partnership between school and home is fostered (Epstein, 2018). Over all, supportive connections in the mesosystem beget positive reading achievement. Conversely, negative interactions in the same system impede reading progress and put students at risk of failure. Quality interactions taking place at the mesosystem and in which the reader is an active member can define to a great extent the developmental reading achievement trajectories. The following figure clearly illustrates this concept: 


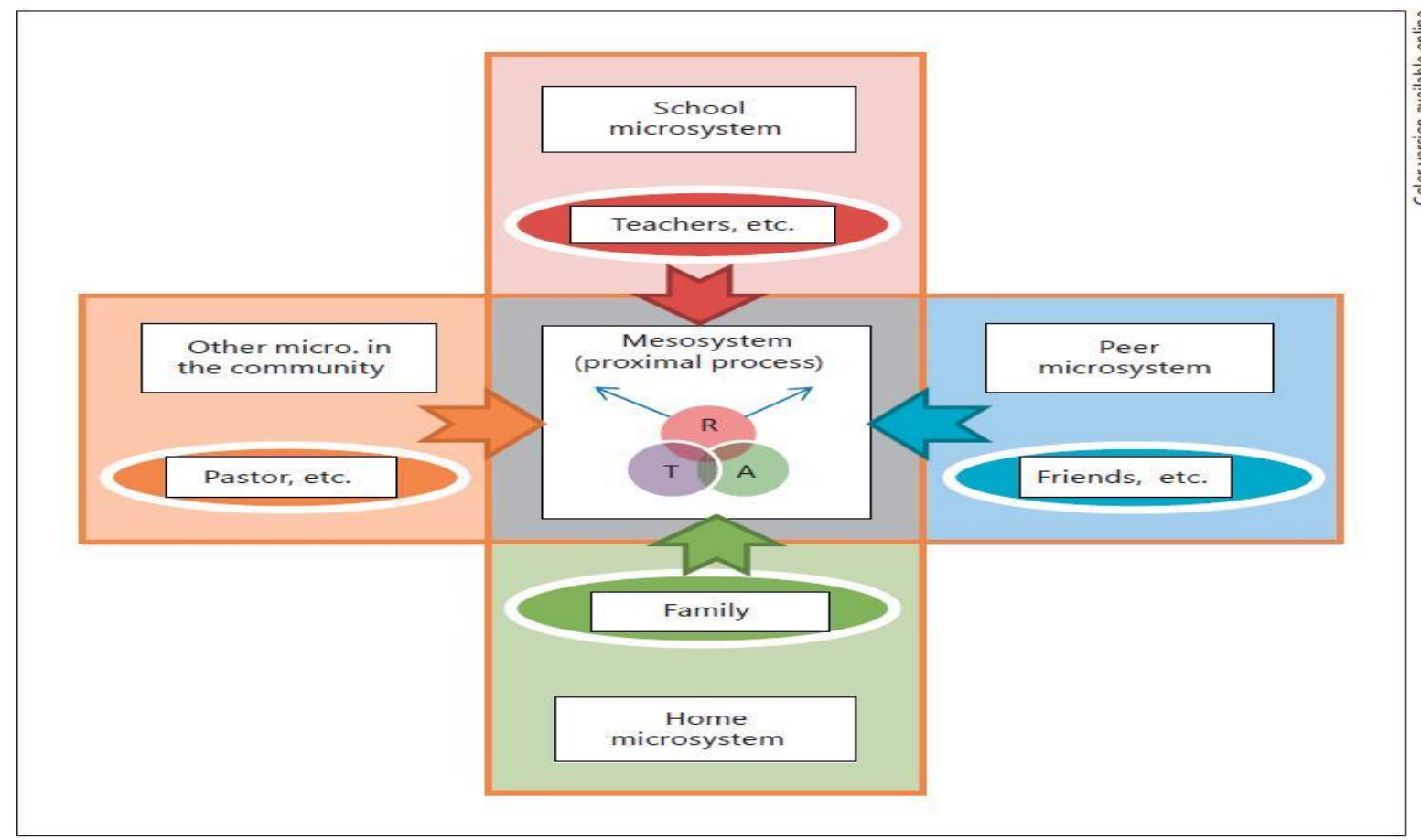

Figure 3: The reading mesosystem (interaction of Microsystems). R=Reader; T=text; $A=A c t i v i t y$ (Adapted from Jaeger, 2017, p. 179)

Beyond the proximal contexts of the microsystems and mesosystems we find the exosystems. The exosystem refers to the interactions of one or more settings that do not directly involve the readers' immediate environment, yet still maintain influence on their reading behavior (Bronfenbrenner\& Morris, 2006). The exosystem implicates parents' work place, neighborhood or community contexts, and family social network, to name a few. The student's reading experience is affected by these systems and provides a comprehensive frame for understanding and interpreting the reading achievement (Aikens \& Barbarin, 2008, p. 235).

Surrounding all the other systems is the macrosystem. The macrosystem is another contextual variable in the bioecological model relevant to the development of students' reading abilities. This system may exist outside the physical environment of the school, family, and neighborhood, yet still exert an influence on the inner systems within the framework. For instance, the multiple contexts in which the school exists such as the educational system, educational reforms, and ministerial guidelines may affect students' reading experience. Also, neighborhoods with disadvantaged families are unlikely to have bookstores, libraries or any educational resources. The absence of educational resources and the lack of exposure to reading activities outside school limit therefore opportunities for extended reading (Jaeger, 2017, p. 181). The influence of the exosystems and macrosystems is illustrated in the following figure: 


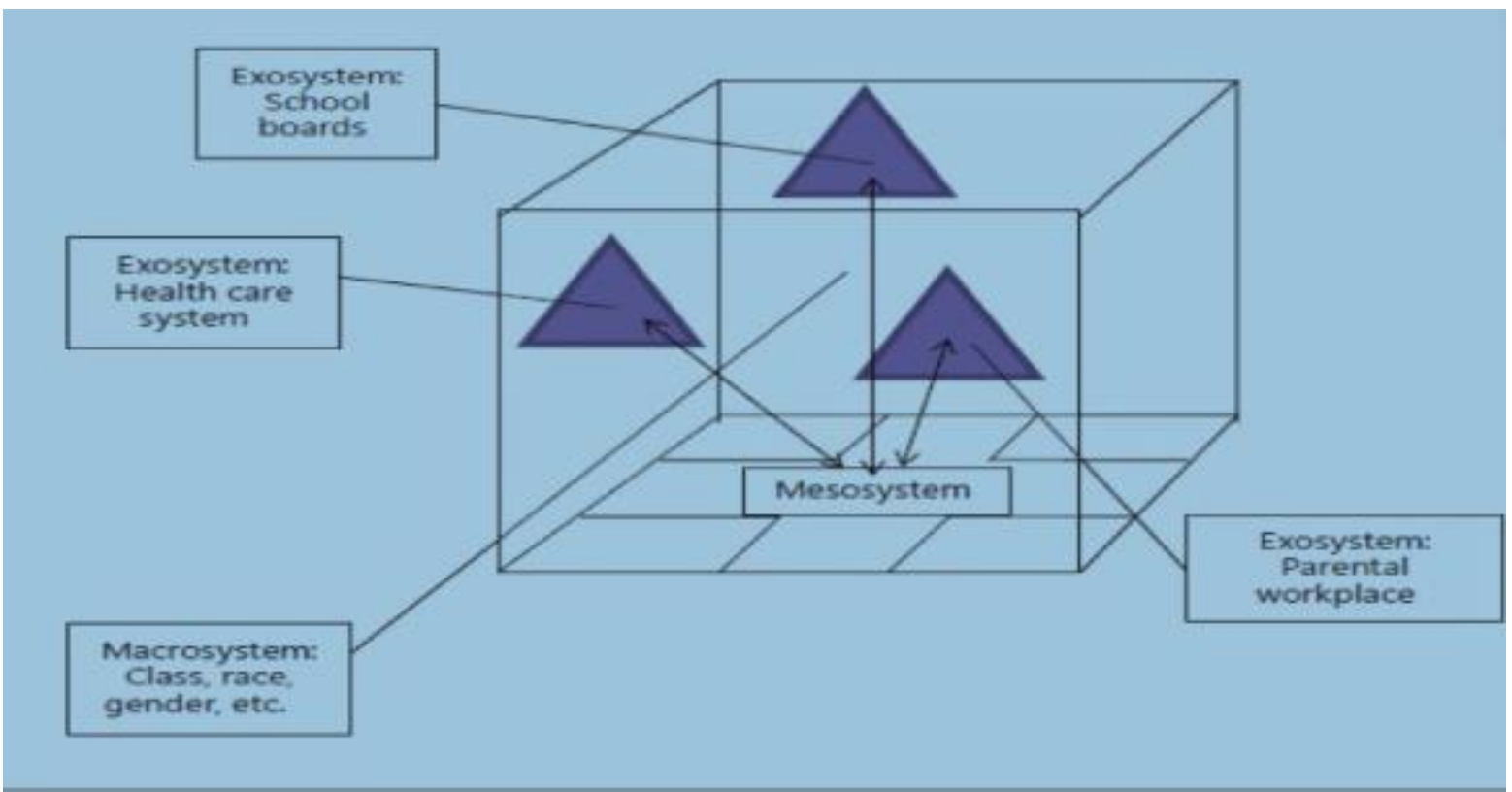

Figure 4: The impact of exo-and macrosystem forces (cited in Jaeger, 2017, p.180)

An additional contextual variable which impacts the reading development is time. Bronfenbrenner and Morris (2006) argue that the amount of time spent on interaction is substantial to "be developmentally effective" (p. 798). Students' engagement in the reading activities necessitates various modes of interactions. These interactions (proximal processes) occur through teacher-student relations, parents-child discussions, student-peers collaboration, and student-text interaction. The extent of contact maintained between the developing reader and the proximal processes in which he/she engages determines the levels of reading proficiency and reading developmental trajectories. The exposure to the reading experience is regulated by a) the duration of the period of exposure and the length of the session, b) the frequency of the sessions, c) the consistency and regularity of the exposure, and d) the timing of interaction and responsiveness to the behavior (Bronfenbrenner \& Evans, 2000, p. 181). Consequently, a student who is exposed to a wide range of texts and engages in positive and regular interactions with the environment has a rich reading experience and therefore is more likely to realize higher reading gains. On the other hand, a student who does not read on a regular basis may encounter reading problems.

\section{BIOECOLOGICAL SYSTEMS THEORY AND READING RESEARCH}

This section provides an inclusive but not an exhaustive review of empirical studies which revitalized interest in the potential of Bronfenrenner theory in explaining reading development. The purpose of this section is to demonstrate the relevance of the bioecological systems framework to reading phenomenon. It paves the ground for inquiry into facilitating the teaching process of the reading process.

Based on an experimental study, Jaeger (2012) investigated the influences of all the many proximal and distal elements ranging from home and school to oppressive race and gender factors on reading development. The author adopted Bronfenbrener's bioecological 


\section{Nadori Neirouz}

model as a conceptual framework. The study traced the reading experiences of 3 readers at risk of failure from grade 4 . The results indicated that children became more effective and engaged readers after the intervention but each child did so in ways that were quite unique. Additionally, the cross-case analysis demonstrated that various ecosystems variables affected their reading development. For reader-1, the type of the reading tasks influenced her reading grades. As for reader-2, his reading developmental abilities were found to be affected by instruction which suited his learning style as well as the increasing level of comfort with his peers. Reader-3 progress was affected by reading texts on topics of great interest but this progress was destabilized by frequent moves caused by his family low socioeconomic status. Over all, the findings supported the potential of supportive learning community, where assistance was provided and success was emphasized.

Avid attention was also given to understanding vocabulary development using Bronfenrenner's theory. Farrant and Zubrik (2012) adopted a bioecologiacal approach (Bronfenbrenner, 1995) to the exploration of children's vocabulary growth. The study examined the interactions occurring among the individual, contextual, and proximal processes involved in children's early vocabulary growth. In other words, the study investigated whether the proximal processes of joint attention and parent-child book reading contributed to the enhancement of children's vocabulary repertoire. The authors analyzed the data from the longitudinal study of Australian children. The findings suggested that the two proximal processes, joint attention and parent-child book reading, were significant predictors. These two proximal processes mediated the effects of individual and contextual factors on early vocabulary development. Farrant and Zubrik (2012) added that individual and contextual assets had developmental importance to the extent that they enhanced, facilitated or restrained the proximal processes through which development took place ( $\mathrm{p}$. 14).

In a broader context, Chiu and Chow (2015) adopted Bronfenbrenner's (2005) ecological system theory to analyze how an ecological model of family and classmate microsystems, classmate family mesosystem, and country macrosystem can help provide a comprehensive account of children's reading achievement in 33 countries. Specifically, they investigated whether classmates' characteristics including family SES, home literacy resources, attitudes towards reading and past reading achievement accounted for reading variance. They extended their analysis to analyze the extent to which these micro and mesosystems related to the macro-system. In other words, the authors investigated how connections among classmates' factors, classmates' family factors, and students' reading achievement vary across countries with differing economic characteristics and cultural values. The model was tested on 141,019 elementary school children using multiple regression coefficient analysis.

The results of this multilevel study revealed that the classmates' characteristics and their parents-related factors both predicted students' reading achievement. Additionally, the findings reported that the links between these variables were stronger in countries with high SES and positive values. To conclude, these findings underscore the importance and relevance of Bronfenbrenner's ecological model in investigating multiple contexts and the 
interactions happening in these contexts and in providing a more comprehensive account of students' reading achievement (Chui \& Chow, 2015, p. 11).

In another large scale study, PIRLS used the ecological theory to investigate of individual and environmental ecologies in which reading comprehension achievement developed. Conducted every five years, 2001, 2006, 2011, 2016, PIRLS evaluates the reading comprehension development in more than 47 countries, including Morocco. It presents a rich array of information about students' home environments and attitudes towards reading, school environments for learning and instruction, teachers' education and training, and classroom characteristics and activities.

A supportive home environment was found to have a strong impact on enhancing students' reading comprehension achievement. Parents' positive attitudes towards reading, availability of home educational resources, parents' involvement in their children's literacy experience, and time devoted to literacy-related activities at home were fundamental factors in the developments of students' reading comprehension achievement (Mullis et al. 2017, p. 12). The findings also indicated that school and classroom systems accounted for great variation in reading comprehension scores. Well-resourced schools, supportive school climate, teachers' qualifications, and quality of reading instruction were all factors contributing to enhanced reading results (Mullis et al. 2017, p. 26). Additionally, individual characteristics such as reading attitudes, motivation, and confidence explained trends in reading achievement. The authors emphasized the reciprocal relationships between these motivational dimensions and reading achievement and claimed that:

Each successive PIRLS assessment has shown a strong positive relationship within countries between student attitudes toward reading and their reading achievement. The relationship is bidirectional, with attitudes and achievement mutually influencing each other. (p. 19)

Bronfenbrenner's ecological model also framed Hawkins' (2017) study. She explicated the reasons for low students' achievement in reading. The author emphasized the importance of the micro, meso, exo, maro-systems influences in understanding the effects of classroom practices, differentiated instruction, professional development, and parental involvement on primary students' reading achievement. Hawkins conducted a case study of seven teachers and used thematic analysis to analyze data collected by means of interviews, class observations and examination of teachers' lesson plans. The results indicated that parental involvement and home environment were the most important factors explaining low reading performance. Based on the findings of her study and Bronfenbrenner's ecological model, the researcher depicted the level where interventions should be focused and accordingly developed a 3-day teacher facilitated family literacy program. The purpose of this program was to equip parents with resources and strategies to enhance the reading achievement of their children at home.

In the Moroccan context, Nadori (2020) conducted a multilevel comparative analysis of public and private high school students' reading comprehension achievement. It investigated how educational opportunities available to students at different levels are distributed across school types and the extent to which an uneven distribution of these 


\section{Nadori Neirouz}

opportunities may channel the school type effects to account for differences in students' reading achievement. This study was informed by Bronfenbrenner and Morris's (2006) bioecological systems theory. This framework provides a holistic approach to interpreting reading development in Morrocan high schools through proximal and distal interactions occurring at different levels of the learners' environment.

The findings demonstrated that private school students outperform their public school peers not only in the overall reading comprehension but also in the four assessed reading comprehension processes. The difference between the two groups of students was a result of the unparalleled distribution of learning opportunities at the home, classroom and school level. Private school students were found to have a higher socioeconomic advantage and therefore have access to more educational resources conductive to better reading gains.

Additionally, private school students' reading achievement was improved by high school responsiveness and collaboration with parents, less school discipline problems, sustained school safety and order. These advantages allowed students attending private schools to have access to educational opportunities directly linked to enhanced reading achievement, namely large school library, quality reading instruction and more exposure to reading lessons, increased teacher involvement in professional development and positive classroom and school learning environment. Such opportunities were limited in public schools however. On the other hand, the findings indicated that school-related variables followed by students' personal assets, predominantly reading self-efficacy exerted a much greater influence on public school students' reading achievement than their socioeconomic status

\section{CONCLUSION}

Although Bronfenbrenner is not a literacy scholar, a key advantage of adopting his bioecological systems theory is its particularity in providing a comprehensive conceptual rationale of how personal attributes and central social contexts interact to explore and explain reading comprehension achievement. Bronfenbrenner's theory has the potential to serve as the foundation for reading research since it has revitalized interest in the range of individual and social factors that influence reading behavior (Jaeger, 2017, p. 164). It also provides a comprehensive framework by perceiving this skill as not being situated exclusively within student's cognition, or within family processes, or within classroom or school processes. Rather, the ecological systems model views reading development as a result of the dynamic interaction among reader, family, classroom, and school system.

This model allows for the investigation of the reading phenomenon from a holistic perspective. It provides an inclusive frame for describing and explaining how the educational opportunities are distributed at the micro, meso, exo, and macro systems and how these systems interact to explain students' reading development. It also delineates how developing readers' individual characteristics transact with both proximal and distal processes to craft their reading ecologies. This implies that this frame allows literacy researchers to incorporate multilevel settings for a more inclusive view of reading.

Another key advantage of this conceptual framework is its multilevel-analysis nature. It is designed in way that fits the hierarchical nature of some data sets. Large scale studies 
generally adopt a hierarchical research sampling designs with students nested within schools and within communities resulting therefore in multiple levels of analysis. This framework allows for an accurate and precise analysis of each level. It explicates the multifaceted forces as being classified in terms of hierarchical systems and influences starting with innermost of the nested system (the reader) and moving to upper level (the macro system). Those systems are characterized by dynamic and bidirectional interactions between various players involved in the reading ecology namely, the reader, the parents, the teachers, the principals, and the peer groups. Therefore, the model helps analyze 1) the relationships between factors that exist between and across levels and which affect students' reading outcomes and 2) the level or levels these interactions take place;

Further, drawing on the ecological framework, precise vision of important targets for education and social policy can be made. In other words, examining the effects of multiple contexts on students' reading achievement is important because investigating influences emanating solely from the family or the school means that policy and program interventions may be narrowly focused. In this sense, this framework allows for a multilevel analysis of readers' strengths and challenges, the proximal process interactions with home and school/classroom microsystems, the mesosystem connections, various exosystem and macrosystem factors, and the role of time. All these factors combined help identify at which level(s) reading inconsistencies have occurred and therefore allow for more accurate and valid interventions.

\section{REFERENCES}

Anderson, R. C. (1978). Schema-directed processes in language comprehension. Cognitive Psychology and Instruction (pp. 67-82). Springer, Boston, MA.

Aikens, N. L., \&Barbarin, O. (2008). Socioeconomic differences in reading trajectories: The contribution of family, neighborhood, and school contexts. Journal of Educational Psychology, 100(2), 235.

Bronfenbrenner, U. (1986). Ecology of the family as a context for human development: Research perspectives. Developmental Psychology, 22(6), 723.

Bronfenbrenner, U., \& Morris, P.A. (1998). The bioecological model of human development.In W. Damon (Series Ed.) \& R.M. Lerner (Vol Ed.), Handbook of child psychology: Vol. 1 Theoretical models of human development (pp. 993-1027). New York, NY: John Riley \& Sons

Bronfenbrenner, U., \& Evans, G. W. (2000). Developmental science in the 21st century: Emerging questions, theoretical models, research designs and empirical finding. Socilal development, 9(1), 115-125.

Bronfenbrenner, U. (2004). Making human beings human: Bioecological perspectives onhuman development. Thousand Oaks, CA: Sage

Bronfenbrenner, U. (2005). Making human beings human: Bioecological perspectives on human development. Sage.

Bronfenbrenner, U., \& Morris, P. A. (2006). The bioecological model of human development.Handbook of Child Psychology. 
Nadori Neirouz

Cheung, D., \& Lai, E. (2013). The effects of classroom teaching on students' self-efficacy for personal development. British Journal of Guidance \& Counselling, 41(2), 164-177.

Cheung, D. (2015). The combined effects of classroom teaching and learning strategy use on students' chemistry self-efficacy. Research in Science Education, 45(1), 101-116.

Chiu, M. M., \& Chow, B. W. Y. (2015). Classmate characteristics and student achievement in33 countries: Classmates' past achievement, family socioeconomic status, educational resources, and attitudes toward reading. Journal of Educational Psychology, 107(1), 152.

Coleman, J. S., Campbell, E. Q., Hobson, C. J., McPartland, J., Mood, A. M., Weinfeld, F. D.,\& Robert, L. (1966). York. Equality of educational opportunity, 2.

Epstein, J. L. (2018). School, family, and community partnerships: Preparing educators and improving schools. Routledge.

Farrant, B. M., \& Zubrick, S. R. (2012). Early vocabulary development: The importance of joint attention and parent-child book reading. First Language, 32(3), 343-364.

Goodman, K. S. (1965). A linguistic study of cues and miscues in reading. Elementary English, 42(6), 639-643.

Hawkins, J. L. (2017). "Figuring It Out": A Qualitative Case Study Exploring the Development of Novice, Alternatively Certified Special Educators in Oklahoma (Doctoral dissertation). Nothwestern Oklahoma University, Oklahoma, USA.

Hedgcock, J. S., \& Ferris, D. R. (2018). Teaching readers of English: Students, texts, and contexts. Routledge.

Jaeger, E. L. (2012). Understanding and Supporting Vulnerable Readers: A Ecological Systems Perspective (Doctoral dissertation). California University, Berkely, USA .

Jaeger, E. L. (2017). Negotiating complexity: A bioecological systems perspective on literacy development. Human Development, 59(4), 163-187.

Lerner, R. M., \& Overton, W. F. (2008). Exemplifying the integrations of the relational developmental system: Synthesizing theory, research, and application to promote positive development and social justice. Journal of Adolescent Research, 23(3), 245255.

Magnusson, D., \& Cairns, R. B. (1996). Developmental science: Toward a unified framework. Cambridge University Press.

Martin, M. O., Mullis, I. V., \& Hooper, M. (2017). Methods and procedures in PIRLS 2016. International Association for the Evaluation of Educational Achievement.

Nadori, N. (2020), Reading comprehension achievement: A comparative study of Moroccan public and private high schools (Unpublished doctoral dissertation). Chouaib Doukkali University, El Jadida, Morocco.

Organisation for Economic Co-operation and Development. (2019), PISA 2018 Results (Volume

III) : What School Life Means for Students' Lives, PISA, Éditions OCDE, Paris, https://doi.org/10.1787/acd78851-en.

Overton, W. F. (2013). A new paradigm for developmental science: Relationism and relational-developmental systems. Applied Developmental Science, 17(2), 94-107. 
Sadoski, M. (2018). Reading comprehension is embodied: Theoretical and practical considerations. Educational Psychology Review, 30(2), 331-349.

Shute, R. H., \& Slee, P. T. (2015). Child development: Theories and critical perspectives. Routledge.

Stanovich, K. E. (1986). Cognitive processes and the reading problems of learning disabledchildren: Evaluating the assumption of specificity. Psychological and Educational Perspectives on Learning Disabilities, 87-131.

Thelen, E., \& Smith, L. B. (1998). Dynamic systems theories. Handbook of Child Psychology.

Unrau, N. J., Rueda, R., Son, E., Polanin, J. R., Lundeen, R. J., \&Muraszewski, A. K. (2018). Can reading self-efficacy be modified? A meta-analysis of the impact of interventions on reading self-efficacy. Review of Educational Research, 88(2), 167204.

Vygotsky, L.S. (1978) Mind in society: the development of higher mental processes.Cambridge, Harvard University Press.

Zimmerman, B. J., \&Kitsantas, A. (2014). Comparing students' self-discipline and selfregulation measures and their prediction of academic achievement. ContemporaryEducational Psychology, 39(2), 145-155. 